\title{
Comparative Response of SC CAKI-1 Renal Tumor to Treatment with Doxorubicin $\mathrm{HCl}$ and Doxorubicin Orotate
}

\author{
Rashida A. Karmali1 ${ }^{*}$, Yulia Maxuitenko¹, Greg Gorman² \\ ${ }^{1}$ SavviPharm Inc. and Tactical Therapeutics Inc., New York, USA \\ ${ }^{2}$ Pharmaceutical Sciences Research Institute, Samford University, Birmingham, USA \\ Email: karmali@aol.com, rashida@tacticaltherapeutics.com
}

Received 10 March 2014; revised 5 April 2014; accepted 13 April 2014

Copyright (C) 2014 by authors and Scientific Research Publishing Inc.

This work is licensed under the Creative Commons Attribution International License (CC BY). http://creativecommons.org/licenses/by/4.0/

(c) (i) Open Access

\begin{abstract}
Background: Doxorubicin (DOX) is an effective treatment for many cancers across the age spectrum, but its therapeutic potential is limited because of dose-dependent relation to both progressive and irreversible cardiomyopathy leading to congestive heart failure. While decreases in cardiotoxicity have been reported with liposomal doxorubicin, the long-term cardiac effects are not known. Orotate salts of cytotoxic drugs have been shown to confer antitumor effects with a better safety profile than unconverted drug, and therefore may offer an improved approach to cancer treatment. Materials and Methods: Male, athymic NCr-nu/nu mice with subcutaneously implanted CAKI-1 human renal tumor xenografts were treated with DOX and its orotate salt (DOX-0) to evaluate antitumor activity, measured by median tumor mass doubling time and tumor weight. Nontumored male, athymic NCr-nu/nu mice were treated with DOX, DOX-O and liposomal doxorubicin formulations to determine DOX concentration in liver and heart; and to evaluate their effect on body weight. Non-tumored female, athymic $\mathrm{NCr}-\mathrm{nu} / \mathrm{nu}$ mice were treated with daunorubicin and daunorubicin orotate to evaluate tolerance. Results: DOX and DOX-O exhibited significant, similar levels of antitumor activity. Mice treated with DOX-O had a lower percentage body weight loss. In the animals treated with DOX, DOX-0, or liposomal doxorubicin, liposomal doxorubicin was associated with the lowest percentage of body weight loss, but the highest concentration of DOX in heart. In daunorubicin tolerance experiments, animals showed a better tolerance for daunorubicin orotate as measured by a smaller percentage change in body weight. Conclusions: DOX-O is effective as an antitumor therapy and may offer a less toxic alternative to DOX for maintaining therapy. The lower percentage of body weight loss in animals treated with DOX-O and daunorubicin orotate is a measure of improved tolerance and may translate into better patient outcomes.
\end{abstract}

${ }^{*}$ Corresponding author. 


\section{Keywords}

\section{Safer Toxicity Profile; Doxorubicin Orotate}

\section{Introduction}

Cardiotoxicity is becoming a more pressing issue as patients with cancer are surviving over the longer term, and greater numbers of patients are treated with adjuvant chemotherapy. Although the anthracycline doxorubicin $\mathrm{HCl}(\mathrm{DOX})$ is effective for many cancers, its use raises concerns that it is cardiotoxic [1]-[6]. Cardiotoxicity is defined as left ventricular dysfunction [7], which may be systolic, diastolic, or both [3]. Changes in LVEF may be asymptomatic [2] [8]. Cardiomyopathy is irreversible [5]-[7] [9], dose dependent, and progressive [5]. There is a clear dose-response relation between anthracycline exposure and cardiomayopathy in both pediatric and adult patients, suggesting shared mechanisms [10].

DOX induces oxidative mechanisms that lead to apoptosis and myocyte death [6] [11] [12] and cause oxidative stress [11] [13] and damage to myocardial cells by generating radicals [3] [6] [12]. DOX affects mitochondrial function [7]. The anthracycline-generated reactive oxygen species (ROS) can generate and maintain mutated mitochondrial DNA [5]. DOX binds to the phospholipid cardiolipin in the inner mitochondrial membrane, disrupting its association with the membrane. This disruption between cardiolipin and the mitochondrial membrane could enhance cytochrome $\mathrm{C}$ release [6]. Cytochrome $\mathrm{C}$ is a proapoptotic protein that results in apoptosis [13].

Congestive heart failure may increase over time [9] and may become evident years after therapy [3] [5] [6]. Damaged mtDNA may give rise to a common mitochondrial DNA deletion, which seems to increase in number over time. The delayed onset of cardiomyopathy long after DOX exposure may be due to mitochondrial DNA alterations that persist or accumulate over the longer term [5].

Troponin I (TNI) is a biomarker for cardiac damage [1] whose early elevation can detect early changes in LV function [6], and predict LV function [4]. In patients with aggressive breast cancer treated with anthracyclines, the percentage of patients with elevated TNI increases with the number of anthracycline cycles [8] [11].

Asymptomatic LV decline can be detected at cumulative DOX doses of $240 \mathrm{mg} / \mathrm{sq}$ meter. Toxicity is dose-dependent, and a dramatic increase in toxicity is seen at cumulative doses over $500 \mathrm{mg} / \mathrm{sq}$ meter [3] [6]. An increased risk of cardiotoxicity is seen even at doses lower than $300 \mathrm{mg} / \mathrm{sq}$ meter [6]. There are lower circulating levels of DOX when it is encased in PEGylated liposomal formulations. These formulations are also designed to be selectively taken up in tumor cells. Decreases in cardiotoxicity have been reported with liposomal DOX [6]; however, the long-term cardiac safety implications of these formulations are not known and need evaluation in large adjuvant trials [3] [14].

Carboxyamidotriazole (5-amino-1(4-(4-chlorobenzoyl)-3, 5-dichlorobenzyl)-1, 2, 3-triazole-4-carboxamide, CAI), a small molecule inhibitor with antiproliferative and antimetastatic effects, reduces VEGF production from tumor and endothelial cells [15]-[17]. Its orotic acid salt, carboxyamidotriazole orotate (CTO), has reduced toxicity, increased oral bioavailability, and stronger efficacy compared to CAI [18]. The orotate salt of the taxane paclitaxel has been found to inhibit the growth of human ovarian tumor xenografts and minimize body weight loss [19].

Given the evidence that orotate salts of cytotoxic drugs can demonstrate antitumor effects with a better safety profile, we hypothesized that the orotate salt of DOX (DOX-O) may offer a potentially improved approach to cancer treatment. This approach also compared DOX-O, a new salt of DOX, versus DOX to determine if DOX$\mathrm{O}$ has a safer profile and equal efficacy compared to DOX.

In this report, we present our evaluation of the antitumor activity of DOX and its orotate salt DOX-O against subcutaneously (s.c.)-implanted CAKI-1 human renal tumor xenografts in male, athymic NCr-nu/nu mice. We conducted a histopathological evaluation of the hearts of animals treated with DOX and DOX-O at an equivalent dose, and measured the DOX concentration.

We also measured the concentration of DOX in the liver and heart of non-tumored male athymic NCr-nu/nu mice treated with DOX-O, DOXIL ${ }^{\circledR}$ (liposomal doxorubicin), and DOX; and evaluated the effect of these formulations on body weight as a measure of tolerance. 
Finally, we compared the tolerance of non-tumored female athymic NCr-nu/nu mice to intravenous (IV) treatment with the anthracycline daunorubicin $\mathrm{HCl}$ and daunorubicin orotate.

We also measured the concentration of DOX in the liver and heart of male athymic NCr-nu/nu mice treated with DOX-O, liposomal doxorubicin, and DOX; and evaluated the effect of these formulations on body weight.

Finally, we compared the tolerance of female athymic NCr-nu/nu mice to intravenous (IV) treatment with the anthracycline daunorubicin $\mathrm{HCl}$ and daunorubicin orotate.

\section{Materials and Methods}

\subsection{Animal Care}

Animals were housed in a pathogen-free barrier facility in micro-isolator cages, five per cage, in a 12-hour light/dark cycle. The animals were observed daily and clinical signs noted. They received filtered Birmingham municipal water and rodent diet (Harlan-Teklad) ad libitum. Cages were changed twice weekly. All experimental procedures were approved by the Institutional Animal Care and Use Committee of Southern Research Institute. Animal laboratories of the Southern Research Institute are AAALAC accredited.

CAKI-1 human renal tumor xenograft: 6-week-old and, for DOX concentration studies, 8 week-old male athymic NCr-nu/nu mice, were purchased from Taconic Farms (Germantown, NY).

Daunorubicin tolerance: Female 6-week-old athymic NCr-nu/nu mice were purchased from Charles River Laboratories (Wilmington, MA).

\subsection{Tumor Model}

\subsubsection{Xenograft}

Each mouse was implanted s.c.in the right flank with a 30 - 40 mg fragment of CAKI-1 human renal tumor xenograft from an in vivo passage using a 13 gauge trocar needle. The day of tumor implantation was designated as Day 0. Tumors were allowed to reach $75-198 \mathrm{mg}$ in weight $\left(75-198 \mathrm{~mm}^{3}\right.$ in size) before the start of treatment. A sufficient number of mice were implanted so that tumors in a weight range as narrow as possible were selected for the trial on the first day of treatment. Animals with tumors in the proper size range were assigned to the various treatment groups. The median tumor weights on the first day of treatment were 135 or $138 \mathrm{mg}$ and the mean tumor weights ranged from 134 to $139 \mathrm{mg}$.

\subsubsection{DOX Concentration and Tolerance}

Animals were non-tumored.

\subsubsection{Daunorubicin Tolerance}

Animals were non-tumored.

\subsection{Drug Formulation}

Xenografts: A $0.8 \mathrm{mg} / \mathrm{mL}$ solution of DOX (doxorubicin hydrochloride USP28, Yick-Vic Chemicals \& Pharmaceuticals (HK) LTD, Kowloon, Hong Kong) was formulated fresh on each day of treatment in saline. The 0.8 $\mathrm{mg} / \mathrm{mL}$ solution was further diluted with saline to 0.53 and $0.35 \mathrm{mg} / \mathrm{mL}$. DOX-O was synthesized from doxorubicin hydrochloride USP28. A $0.975 \mathrm{mg} / \mathrm{mL}$ solution of DOX-O was formulated fresh in saline on each day of treatment for xenograft and DOX-O concentration studies. The $0.975 \mathrm{mg} / \mathrm{mL}$ solution was further diluted with saline to 0.65 and $0.43 \mathrm{mg} / \mathrm{mL}$. Both compounds and the vehicle were administered to mice by exact individual animal's body weight on each day of treatment with an injection volume of $0.1 \mathrm{~mL} / 10 \mathrm{~g}$ of body weight.

DOX Concentration and Tolerance: A clinical formulation of doxorubicin $\mathrm{HCl}$ liposome injection, 2 $\mathrm{mg} / \mathrm{mL}$ (Ortho Biotech Products, L.P.) was diluted with $5 \%$ dextrose solution (D5W) to $0.8 \mathrm{mg} / \mathrm{mL}$ on each day of treatment. A clinical formulation of Adriamycin ${ }^{\circledR}$ (Doxorubicin $\mathrm{HCl}$ ) Injection, USP (2 mg/mL, Bedford Laboratories) was diluted to $0.8 \mathrm{mg} / \mathrm{mL}$ with saline on each day of treatment. All three compounds were administered to mice by exact individual animal's body weight on each day of treatment.The injection volume was 0.1 $\mathrm{mL} / 10 \mathrm{~g}$ of body weight.

Daunorubicin Tolerance: Daunorubicin $\mathrm{HCl}$ was supplied by Southern Research Institute. Saline was purchased from Nova-Teck, Inc. A $1.0 \mathrm{mg} / \mathrm{mL}$ solution (on Days 1, 5, and 9) or a $2.0 \mathrm{mg} / \mathrm{mL}$ solution (on Days 11 
and 15) of daunorubicin $\mathrm{HCl}$ in saline was formulated each day of treatment. A $1.243 \mathrm{mg} / \mathrm{mL}$ solution (on Days 1,5 , and 9) or a $2.486 \mathrm{mg} / \mathrm{mL}$ solution (on Days 11 and 15) of daunorubicin orotate in saline was formulated on each day of treatment.

Daunorubicin $\mathrm{HCl}$ and daunorubicin orotate were administered to mice by exact individual animal's body weight on each day of treatment. The treatment volume was $0.1 \mathrm{~mL} / 10 \mathrm{~g}$ body weight.

\subsection{Drug Treatment}

Xenografts: Six groups of 10 mice per group were treated with DOX or an equivalent dose of DOX-O (based on DOX MW of 580.0 and DOX orotate MW of 707.0). DOX doses were selected based on the published maximum tolerated dosage for DOX of $8.0 \mathrm{mg} / \mathrm{kg}$ when administered i.p. on a q4d x 3 schedule.

Animals in all six groups were injected intravenously (IV) once every 4 days for a total of four injections (q4d $\mathrm{x} 4$, Days 13, 17, 21, and 25). Animals in the control group were treated with vehicle (saline). Three groups were treated with DOX 8.0, 5.3, and $3.5 \mathrm{mg} / \mathrm{kg}$. Three groups were treated with DOX-O 9.75, 6.5, and 4.3 $\mathrm{mg} / \mathrm{kg}$.

DOX Concentration and Tolerance in Non-Tumored Animals: Animals in the control group were untreated. Animals in the treatment groups were injected IV once every 4 days for a total of four injections (Q4d $\mathrm{x}$ 4, Days 1, 5, 9, and 13). Three groups of five mice per group were treated with DOX or an equivalent dose liposomal doxorubicin, or DOX-O, based on DOX HCl MW of 580.0 and DOX-O MW of 707.0. Animals received DOX-O $9.75 \mathrm{mg} / \mathrm{kg}$, liposomal doxorubicin $8.0 \mathrm{mg} / \mathrm{kg}$, or DOX $8.0 \mathrm{mg} / \mathrm{kg}$.

Daunorubicin Tolerance in Non-Tumored Animals: Two groups of five mice per group were treated with daunorubicin or an equivalent dose of daunorubicin orotate, based on MW of daunorubicin orotate of 701 and daunorubicin $\mathrm{HCl}$ of 564. All treatments were administered IV and were initiated on Day 1. Animals in both groups were treated once every 4 days for a total of three injections (Q4Dx3, Days 1, 5, and 9) followed by two injections at a doubled dose given four days apart (Q4Dx2, Days 11 and 15). Animals in the first group were treated with daunorubicin $\mathrm{HCl} 10 \mathrm{mg} / \mathrm{kg}$ followed by $20 \mathrm{mg} / \mathrm{kg}$. Animals in the second group were treated with daunorubicin orotate $12.43 \mathrm{mg} / \mathrm{kg}$ followed by $24.86 \mathrm{mg} / \mathrm{kg}$. The doubled doses were administered to observe toxicity.

\subsection{Parameters Evaluated}

Xenografts: The number of nonspecific deaths, number of partial and complete tumor regressions, number of tumor-free survivors, and the individual animal's median time to reach two tumor mass doublings were determined. The individual animal's time to reach two tumor mass doublings was used in the calculation of the overall delay in the growth of the median tumor (T-C). Comparison of the median tumor weight in the treatment groups (T) to the median tumor weight in the control group (T/C x 100\%) on Day 26 (the day the animals in the vehicle-treated control group were euthanized) was used for an additional evaluation of the antitumor efficacy of the test compounds. Heart tissue was collected for determination of DOX concentration.

DOX Concentration and Tolerance in Non-Tumored Animals: Heart and liver tissue were collected for determination of DOX concentration. Group mean body weights on each day of data collection were calculated. Change in mean body weight on each day of data collection relative to the mean body weight on Day 1 (in grams and as a percent) was calculated for each group.

Daunorubicin Tolerance in Non-Tumored Animals: Days of deaths and 21-day survival were evaluated. On each day of data collection, group mean body weights and change in mean body weight relative to the mean body weight on Day 1 (in grams and as a percent) were calculated.

\subsection{Evaluation Procedures}

\subsubsection{Tumor Measurements and Body Weights}

Xenografts: The s.c. tumors were measured and the animals were weighed twice weekly beginning on the first day of treatment. Tumor volume was determined by caliper measurements $(\mathrm{mm})$ and using the formula for an ellipsoid sphere: $\mathrm{L} \times \mathrm{W}^{2} / 2=\mathrm{mm}^{3}$, where $\mathrm{L}$ and $\mathrm{W}$ refer to the larger and smaller perpendicular measurements, respectively. This formula was also used to calculate tumor weight, assuming unit density $\left(1 \mathrm{~mm}^{3}=1 \mathrm{mg}\right)$.

DOX Tolerance: The non-tumored animals were weighed twice weekly starting with the first day of treatment. 
Daunorubicin Tolerance: Non-tumored animals were checked and mortality was recorded once daily. The animals were weighed three times a week starting on the first day of treatment.

\subsubsection{Tissue Collection}

Xenografts: On Day 26, 1 day after the injection was administered, animals in the vehicle-treated control, DOX $8.0 \mathrm{mg} / \mathrm{kg}$, and DOX-O $9.75 \mathrm{mg} / \mathrm{kg}$ groups were euthanized and their hearts collected. Each heart was bisected vertically. One half of each heart of five mice from the vehicle-treated control and all 10 mice from the DOX 8.0 $\mathrm{mg} / \mathrm{kg}$, and DOX-O $9.75 \mathrm{mg} / \mathrm{kg}$ groups were preserved in 10\% formalin. Hearts fixed in $10 \%$ buffered formalin were submitted for histopathological evaluation. The other half of each heart of those 25 animals was snap frozen in liquid nitrogen. Hearts of five remaining animals from the untreated control group were snap frozen whole in liquid nitrogen. Frozen heart samples were stored at $-84^{\circ} \mathrm{C}$ until submitted for the determination of DOX concentration.

DOX Concentration Non-Tumored Animals: On Day 14, 1 day after the final injection was administered on Day 13, non-tumored animals in all groups were euthanized and their livers and hearts collected, weighed, and snap frozen in liquid nitrogen. Frozen livers and hearts samples were stored at approximately $80^{\circ} \mathrm{C}$ until submitted for the determination of DOX concentration.

\subsection{Study Duration}

Xenografts: The study was terminated 95 days after tumor implantation. Any animal whose tumor reached $4000 \mathrm{mg}$ in weight was euthanized prior to the scheduled day of study termination. Animals in the vehicle-treated control group and the groups treated with DOX $8.0 \mathrm{mg} / \mathrm{kg}$ and DOX-O $9.75 \mathrm{mg} / \mathrm{kg}$ were euthanized on Day 26 for heart collection.

DOX Concentration and Tolerance Non-Tumored Animals: On Day 26, 1 day after the final injection was administered on Day 25, tumored animals were euthanized and their livers and hearts collected, weighed, and snap frozen in liquid nitrogen. Frozen livers and hearts samples were stored at approximately- $80^{\circ} \mathrm{C}$ until submitted for the determination of the concentration of doxorubicin.

Daunorubicin Tolerance Non-Tumored Animals: The last animal died on Day 21.

\subsection{Statistical Analysis}

Xenografts: The individual animal's time to reach two tumor mass doublings was used as the endpoint in a life tables analysis (stratified Kaplan-Meier estimation followed by the Mantel-Haenszel log-rank test) in order to statistically compare the growth data between groups. A life tables analysis allows comparison of the growth data between the groups using the animals whose tumors did not reach the evaluation point, by censoring them. Individual tumor weights on Day 26 were compared by a Student's t-test or a Mann-Whitney rank sum test. A nonparametric test was used when the data set did not pass the normality test. The concentrations of DOX in the heart tissue between the groups were analyzed by a Student's t-test or a Mann-Whitney test.

DOX Concentration and Tolerance: The concentrations of DOX in the heart and liver tissue between the groups were analyzed by t-test or Mann-Whitney test. A pooled estimate of the body weight variance was computed from ANOVA and utilized by a Dunnett's post analysis comparison of each treatment group with the control group for each study day interval.

Daunorubicin Tolerance: Sigma Stat version 3.5 statistical software was used to compare the body weights. The individual animals' body weights were used as endpoints in a t-test. The difference between the groups was considered to be significant if the $P$ value was $\leq 0.05$.

\section{Results}

\subsection{CAKI-1 Renal Tumor Xenografts}

Control, vehicle-treated CAKI-1 human renal tumor xenografts grew progressively in all 10 animals. The median tumor reached two tumor mass doublings in 9.4 days, and 1019 mg in weight on Day 26.

Four groups tolerated treatment without deaths. Four animals died in the remaining two groups: three animals in the DOX $3.5 \mathrm{mg} / \mathrm{kg}$ group, whose deaths were not related to treatment, and one accidental death in the DOX-O $4.3 \mathrm{mg} / \mathrm{kg}$ group. 


\subsubsection{Antitumor Activity Treatment Groups versus Vehicle Controls}

A summary of the CAK-1 experimental results, including tumor regression, tumor-free survival, median days to two doublings, median growth delay, and median T/C are presented in Table 1.

When treatment groups were compared to controls, statistically significant antitumor activity was observed for all six groups treated with DOX and DOX-O (Table 2).

Nine of 10 animals in the group treated with DOX at $8.0 \mathrm{mg} / \mathrm{kg}$, and four of 10 animals in the group treated with DOX-O at $9.75 \mathrm{mg} / \mathrm{kg}$ were tumor-free at the time of heart collection on Day 26.Tumors of the animals in the groups treated with DOX at $8.0 \mathrm{mg} / \mathrm{kg}$ and DOX-O at $9.75 \mathrm{mg} / \mathrm{kg}$ did not reach the evaluation point by the day of termination (median time to reach two tumor mass doublings was > 13.0 days). Response of the CAKI-1 renal tumor xenografts to the treatment with DOX and DOX-O are graphically presented in Figure 1 and Figure 2, respectively.

All 10 tumors in the group treated with DOX $5.3 \mathrm{mg} / \mathrm{kg}$, eight of 10 tumors at the equivalent DOX-O dose of $6.5 \mathrm{mg} / \mathrm{kg}$, seven of 10 tumors in the group treated with DOX $3.5 \mathrm{mg} / \mathrm{kg}$, and three of nine tumors at the equivalent DOX-O dose of $4.3 \mathrm{mg} / \mathrm{kg}$ underwent complete tumor regression. One animal from each of the four groups was still tumor-free on the day of study termination, Day 95.

Table 1. Response of SC CAKI-1 renal tumor to treatment with doxorubicin $\mathrm{HCl}$ and doxorubicin orotate.

\begin{tabular}{|c|c|c|c|c|c|c|c|c|}
\hline \multicolumn{2}{|c|}{ Treatment } & \multicolumn{3}{|c|}{ Tumor Regression } & \multirow[b]{2}{*}{$\begin{array}{c}\text { Tumor-free } \\
\text { Survival Total }\end{array}$} & \multirow[b]{2}{*}{$\begin{array}{l}\text { Median Days } \\
\text { to } 2 \text { Doublings }\end{array}$} & \multirow[b]{2}{*}{$\begin{array}{l}\text { Growth } \\
\text { Delay } \\
(T-C)^{a}\end{array}$} & \multirow[b]{2}{*}{$\begin{array}{l}\text { Median T/C } \\
\text { (\%) Day } 26\end{array}$} \\
\hline Compound & $\begin{array}{l}\text { Dose } \\
\mathbf{m g} / \mathbf{k g}\end{array}$ & $\begin{array}{l}\text { Number of } \\
\text { Partial }\end{array}$ & $\begin{array}{c}\text { Number of } \\
\text { Complete }\end{array}$ & $\begin{array}{c}\text { Duration } \\
\text { Med/Range } \\
\text { (Days) }\end{array}$ & & & & \\
\hline Control $^{\mathrm{b}}$ & 0 & & & & $0 / 10$ & 9.4 & & \\
\hline $\mathrm{DOX}^{\mathrm{b}}$ & 8 & 0 & 9 & & $9 / 10$ & $>13$ & $>3.6$ & 0 \\
\hline DOX & 5.3 & 0 & 10 & $\begin{array}{c}34.3 \\
28-48\end{array}$ & $1 / 10$ & 67 & 57.6 & 0 \\
\hline $\mathrm{DOX}$ & 3.5 & 2 & 7 & $\begin{array}{c}23.6 \\
1-34\end{array}$ & $1 / 10$ & 54 & 45.0 & 10 \\
\hline DOX-O & 9.75 & 2 & 4 & & $4 / 10$ & $>13$ & $>3.6$ & 6 \\
\hline DOX-O & 6.5 & 2 & 8 & $\begin{array}{c}28.9 \\
11-42\end{array}$ & $1 / 10$ & 58.7 & 49.3 & 8 \\
\hline DOX-O & 4.3 & 1 & 3 & $\begin{array}{c}9.3 \\
2-25\end{array}$ & $1 / 10$ & 41.2 & 31.8 & 14 \\
\hline
\end{tabular}

${ }^{\mathrm{a}}$ Growth delay calculations are based on median days to 2 doublings. ${ }^{\mathrm{b}}$ Groups were killed at 26 days and hearts harvested for histopathological examination and DOX concentration.

Table 2. Summary statistical analysis results CAKI-1 xenografts.

\begin{tabular}{|c|c|c|}
\hline \multirow{2}{*}{$\begin{array}{c}\text { Group Pairs } \\
\text { mg/kg }\end{array}$} & \multicolumn{2}{|c|}{ P Values } \\
\hline & Time to Two Tumor Doublings ${ }^{a}$ & Tumor Weight on Day $26^{b}$ \\
\hline Control v. 8.0 DOX & UE & $<0.0001$ \\
\hline Control v. 5.3 DOX & $0.000^{*}$ & $<0.0001$ \\
\hline Control v. 3.5 DOX & 0.000 & $<0.0001$ \\
\hline Control v. 9.75 DOX-O & UE & $<0.0001$ \\
\hline Control v. 6.5 DOX-O & 0.000 & $<0.0001$ \\
\hline Control v. 4.3 DOX-O & 0.000 & $<0.0001$ \\
\hline 8.0 DOX v. 9.75 DOX-O & UE & 0.0623 \\
\hline 5.3 DOX v. 6.5 DOX-O & 0.176 & 0.0374 \\
\hline 3.5 DOX v. 4.3 DOX-O & 0.035 & 0.0421 \\
\hline
\end{tabular}

athe Mann-Whitney rank sum test. ${ }^{b}$ the t-test or the Mann-Whitney rank sum test. UE-unevaluable. ${ }^{*}$ p value is less than 0.001. 


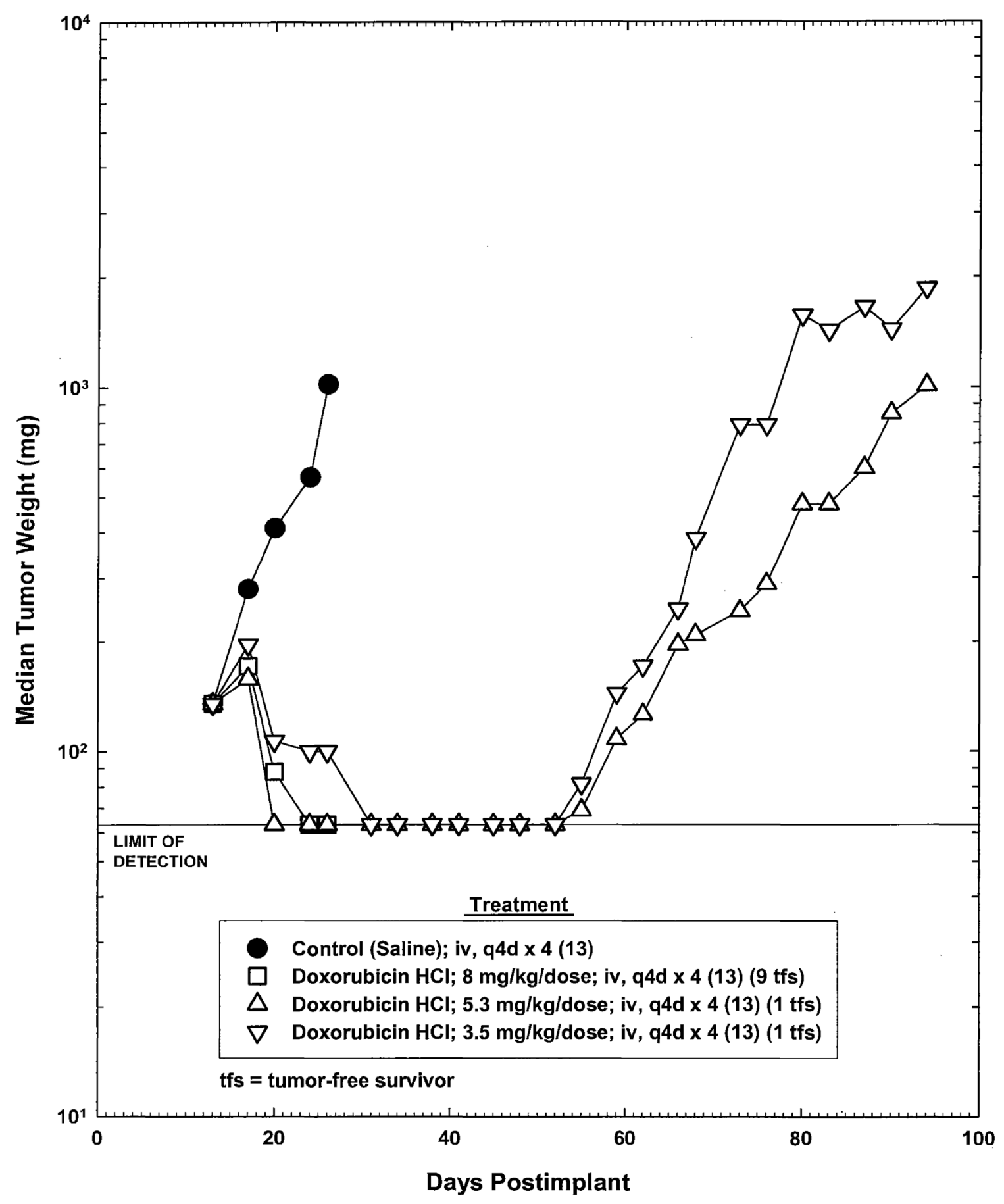

Figure 1. Response of SC CAKI-1 renal tumor to treatment with doxorubicin $\mathrm{HCl}$.

Graphical comparison of the response of the CAKI-1 renal tumor xenografts to the treatment with the highest dosage of DOX tested, $8.0 \mathrm{mg} / \mathrm{kg}$, and DOX-O at the equivalent dosage $(9.75 \mathrm{mg} / \mathrm{kg})$ is presented in Figure 3 .

1) Tumor Weights and Tumor Mass Doubling Time DOX versus Controls

The tumor weights of individual animals on Day 26 in all three groups treated with DOX and all three groups treated with DOX-O were statistically significant $(\mathrm{P}<0.0001)$ compared to those in the control group (Table 2$)$. Times to reach two tumor mass doublings were statistically significant for $5.3 \mathrm{mg} / \mathrm{kg}$ and $3.5 \mathrm{mg} / \mathrm{kg} \mathrm{DOX}(\mathrm{P}=$ $0.000)$, and $6.5 \mathrm{mg} / \mathrm{kg}$ and $4.3 \mathrm{mg} / \mathrm{kg} \mathrm{DOX}-\mathrm{O}(\mathrm{P}=0.000)$ compared to controls. The DOX $8.0 \mathrm{mg} / \mathrm{kg}$ and cor- 


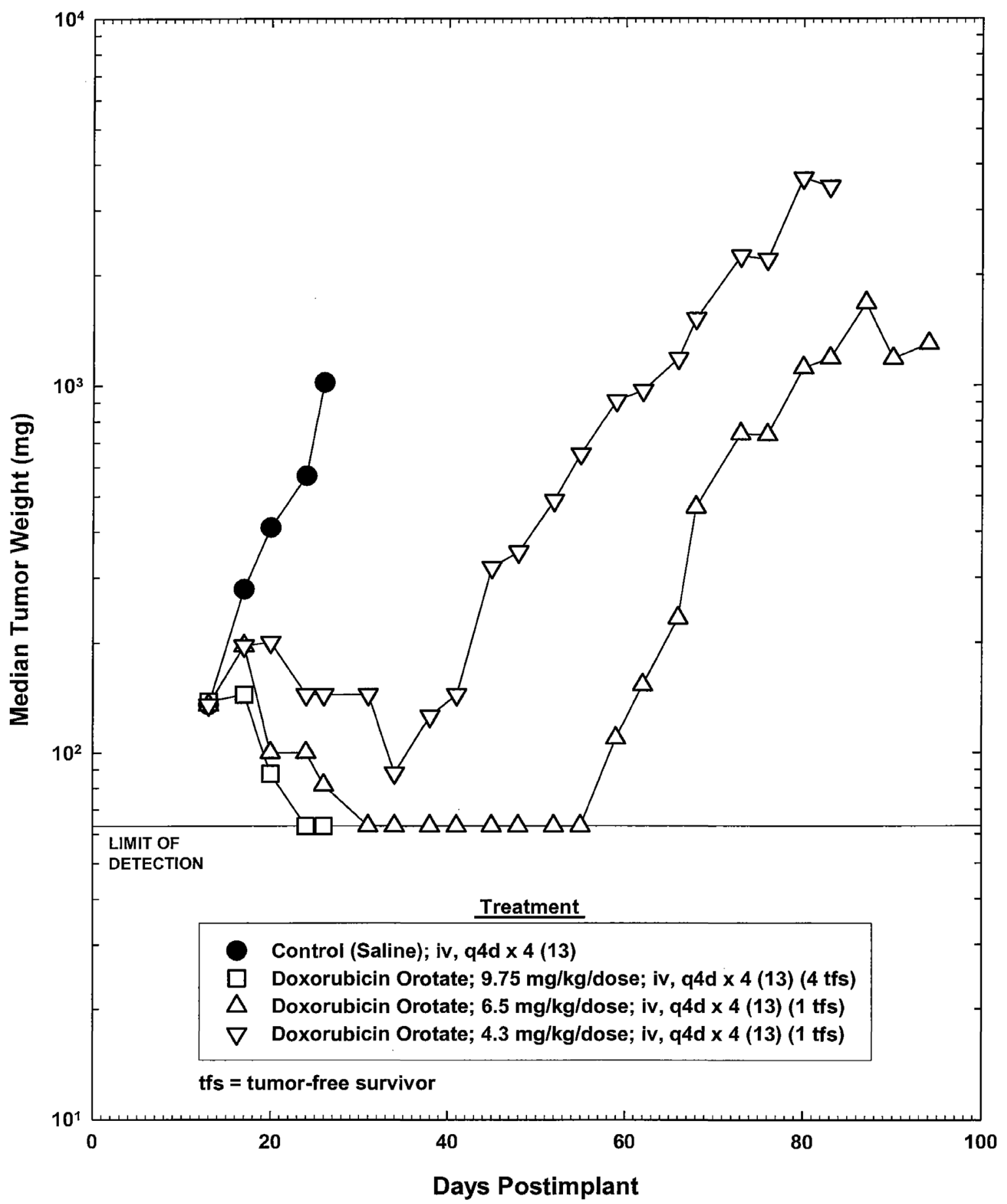

Figure 2. Response of SC CAKI-1 renal tumor to treatment with doxorubicin orotate.

responding DOX-O $9.75 \mathrm{mg} / \mathrm{kg}$ doses were unevaluable because the animals were sacrificed for heart collection prior to reaching the evaluation point.

2) DOX versus DOX-O

The tumor weights of individual animals on Day 26 were statistically significant $(P=0.0374)$ in the group treated with DOX $5.3 \mathrm{mg} / \mathrm{kg}$ compared to the group treated with the corresponding equivalent dose of $6.5 \mathrm{mg} / \mathrm{kg}$ DOX-O. DOX administration resulted in smaller tumors on Day 26. Individual animal's times to reach two tu- 


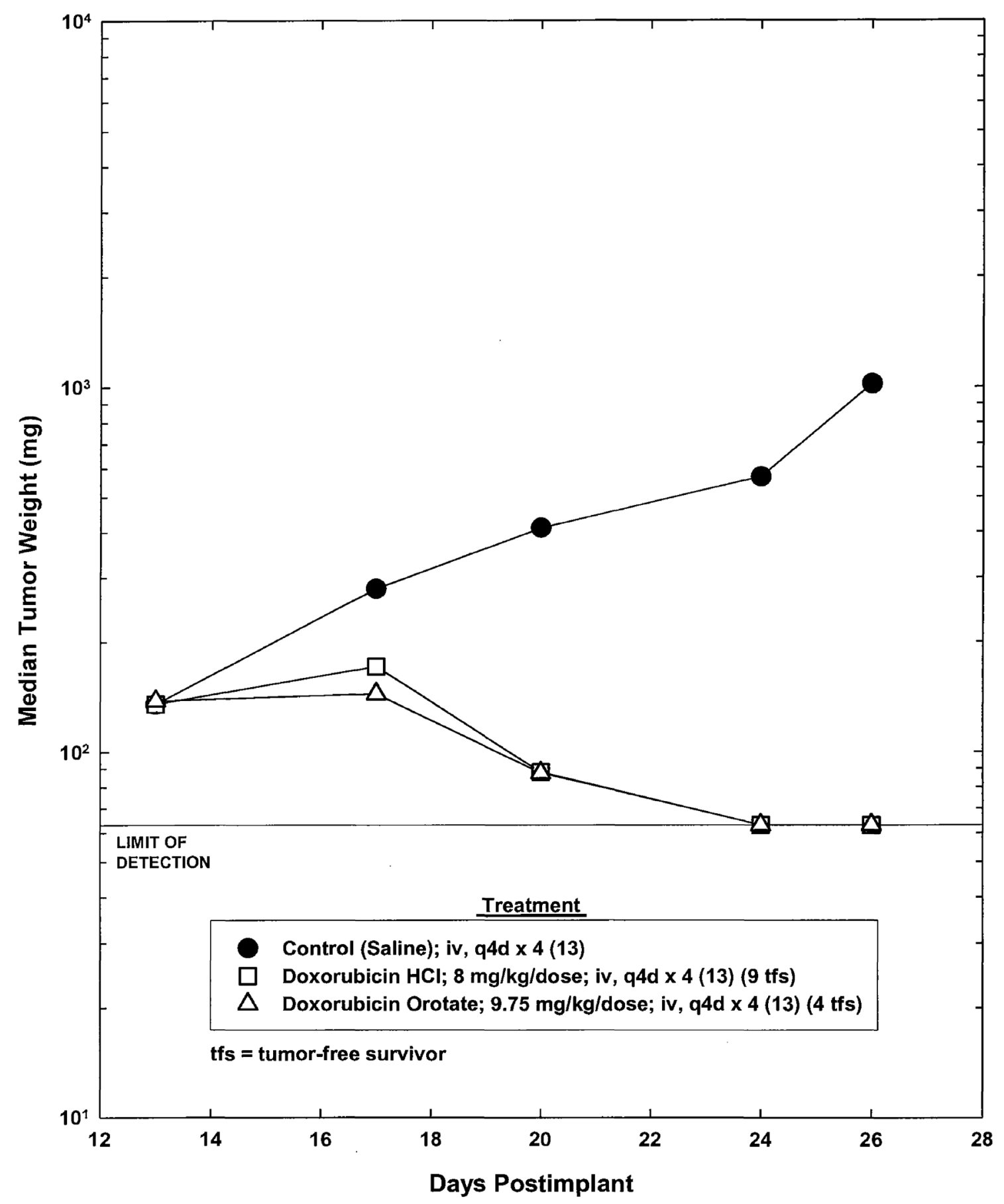

Figure 3. Response of SC CAKI-1 renal tumor to treatment with doxorubicin $\mathrm{HCl}$ and doxorubicin orotate.

mor mass doublings were not statistically different in the group treated with DOX $5.3 \mathrm{mg} / \mathrm{kg}$ compared the group treated with the corresponding equivalent dose of $6.5 \mathrm{mg} / \mathrm{kg}$ DOX-O (Table 2).

The tumor weights of individual animals and their time to reach two tumor mass doublings on Day 26 were statistically significant ( $\mathrm{P}=0.041$ and $\mathrm{P}=0.035$, respectively) in the group treated with DOX $3.5 \mathrm{mg} / \mathrm{kg}$ compared to the group treated with the corresponding equivalent dose of $4.3 \mathrm{mg} / \mathrm{kg}$ DOX-O. DOX administration resulted in greater inhibition of tumor growth (Table 2).

However, the tumor weights of individual animals on Day 26 in the group treated with DOX $8.0 \mathrm{mg} / \mathrm{kg}$ were 
not statistically different from those in the group treated with the corresponding equivalent dose of DOX-O 9.75 $\mathrm{mg} / \mathrm{kg}$ (Table 2).

\subsubsection{Body Weight Loss in Xenografts}

Maximum tolerated dosage (MTD) is defined as the maximum dosage that does not produce death or more than $20 \%$ average body weight loss during and within 14 days of the end of the treatment. For the tumored animals, average maximum body weight loss associated with DOX ranged from $31 \%(8.0 \mathrm{mg} / \mathrm{kg})$ to $9 \%$ (3.5 $\mathrm{mg} / \mathrm{kg})$, and for DOX-O, $25 \%(9.75 \mathrm{mg} / \mathrm{kg})$ to $5 \%(4.3 \mathrm{mg} / \mathrm{kg})$. Animals in the groups treated with DOX at $5.3 \mathrm{mg} / \mathrm{kg}$ and $3.5 \mathrm{mg} / \mathrm{kg}$, and DOX-O at $6.5 \mathrm{mg} / \mathrm{kg}$ and $4.3 \mathrm{mg} / \mathrm{kg}$ re-gained weight after the end of the treatment. The MTD for DOX was $5.3 \mathrm{mg} / \mathrm{kg}$, and for DOX-O, $6.5 \mathrm{mg} / \mathrm{kg}$. All groups except the $4.3 \mathrm{mg} / \mathrm{kg}$ DOX-O had statistically significant differences from the control animals (Table 3).

\subsubsection{DOX Concentration in Tumored Animals}

The difference in the concentration of DOX in the heart tissue between the group treated with DOX $8.0 \mathrm{mg} / \mathrm{kg}$ and DOX-O $9.75 \mathrm{mg} / \mathrm{kg}$ was not statistically significant. Concentration of DOX in heart tissue averaged 7398 ng/g for DOX 8.0 and $5264 \mathrm{ng} / \mathrm{g}$ in DOX-O $9.75 \mathrm{mg} / \mathrm{kg}$ (28\% drop). The mineralization and myofiber degeneration noted microscopically were observed in treated animals, but no definite test-article-related occurrence was observed.

\subsection{DOX Concentration in Non-Tumored Animals}

\subsubsection{DOX Concentration in Heart and Liver}

The concentration of DOX was measured in liver and heart of male NCr-nu/nu mice administered DOX 8.0 $\mathrm{mg} / \mathrm{kg}$ alone, DOX-O $9.75 \mathrm{mg} / \mathrm{kg}$ alone, and liposomal doxorubicin $8.0 \mathrm{mg} / \mathrm{kg}$ alone. The effect of the three DOX formulations on body weight was also evaluated.

The concentration of DOX in the liver of the animals treated with liposomal doxorubicin was statistically higher than in the liver of the animals treated with DOX-O $(\mathrm{P}=0.008)$ or DOX $(\mathrm{P}<0.001)$. The concentration of DOX in the livers of the animals treated with DOX-O was statistically higher than in the livers of those treated with DOX $(\mathrm{P}=0.006)$.

The concentration of DOX in the hearts of the animals treated with liposomal doxorubicin (8980 $\pm 2250 \mathrm{SD})$ was statistically higher than in the heart of the animals treated with DOX orotate $(1200 \pm 144 \mathrm{SD})(\mathrm{P}=0.008)$ or DOX $(1196 \pm 191 \mathrm{SD})(\mathrm{P}=0.008)$. However, the concentration of DOX in the hearts of the animals treated with DOX-O and DOX were similar, in contrast to results obtained in tumored animals.

\subsubsection{Body Weight Loss in Non-Tumored Animals}

Animals in the untreated control group gained weight over the course of the experiment. Treatment with all three DOX formulations was tolerated without deaths. Average maximum body weight losses, observed on Day 14, were DOX-O $9.75 \mathrm{mg} / \mathrm{kg}, 20 \%$; liposomal doxorubicin8.0 mg/kg, 11\%; and DOX $8.0 \mathrm{mg} / \mathrm{kg}, 26 \%$. Thus, the DOX $8.0 \mathrm{mg} / \mathrm{kg}$ was above the MTD (Table 4).

For these non-tumored animals, no significant differences in body weights were noted except on Day 12 for the group treated with DOX $8.0 \mathrm{mg} / \mathrm{kg}$, which was statistically lower $(\mathrm{p}<0.01)(19.5 \%$ mean body weight

\begin{tabular}{|c|c|c|c|c|c|c|c|}
\hline $\begin{array}{l}\text { Study Interval } \\
\text { (Day) }\end{array}$ & $\begin{array}{l}0 \mathrm{mg} / \mathrm{kg} \\
\text { Control }\end{array}$ & $\begin{array}{c}8.0 \mathrm{mg} / \mathrm{kg} \\
\text { DOX }\end{array}$ & $\begin{array}{c}5.3 \mathrm{mg} / \mathrm{kg} \\
\text { DOX }\end{array}$ & $\begin{array}{c}3.5 \mathrm{mg} / \mathrm{kg} \\
\text { DOX }\end{array}$ & $\begin{array}{l}9.35 \mathrm{mg} / \mathrm{kg} \\
\text { DOX-O }\end{array}$ & $\begin{array}{c}6.5 \mathrm{mg} / \mathrm{kg} \\
\text { DOX-O }\end{array}$ & $\begin{array}{c}4.3 \mathrm{mg} / \mathrm{kg} \\
\text { DOX-O }\end{array}$ \\
\hline 13 & 28.0 & 28.8 & 27.2 & 28.0 & 26.8 & 27.7 & 27.4 \\
\hline 17 & 27.6 & 26.6 & 25.9 & 26.5 & 24.3 & 26.0 & 26.7 \\
\hline 20 & 27.9 & 25.7 & 25.2 & 26.1 & $23.7^{\mathrm{a}}$ & 25.9 & 26.7 \\
\hline 24 & 28.4 & $22.0^{\mathrm{a}}$ & $24.2^{\mathrm{a}}$ & $25.4^{\mathrm{b}}$ & $21.4^{\mathrm{a}}$ & $25.3^{\mathrm{b}}$ & 25.9 \\
\hline 26 & 29.6 & $20.0^{\mathrm{a}}$ & $23.9^{\mathrm{a}}$ & $26.2^{\mathrm{b}}$ & $20.0^{\mathrm{a}}$ & $26.0^{\mathrm{b}}$ & 27.2 \\
\hline
\end{tabular}

${ }^{\mathrm{a}}$ Significantly different from the control; $(\mathrm{p}<0.01) .{ }^{\mathrm{b}}$ Significantly different from the control; $(\mathrm{p}<0.05)$. 
Table 4. Mean gross body weight percent change DOX tolerance experiments in non-tumored animals.

\begin{tabular}{|c|c|c|c|c|c|}
\hline \multirow{2}{*}{ Compound } & \multicolumn{5}{|c|}{ Day } \\
\hline & 1 & 5 & 8 & 12 & 14 \\
\hline \multicolumn{6}{|l|}{ Control $0 \mathrm{mg} / \mathrm{kg}$} \\
\hline Mean gross body weight (g) & 25.7 & 26.4 & 27.6 & 26.7 & 26.8 \\
\hline Mean gross body weight change (g) & & +0.7 & +1.9 & +1.0 & +1.1 \\
\hline Mean gross body weight change (\%) & & 3 & 7 & 4 & 4 \\
\hline \multicolumn{6}{|l|}{ DOX orotate 9.75 mg/kg } \\
\hline Mean gross body weight (g) & 27.6 & 27.0 & 26.9 & 24.1 & 22.1 \\
\hline Mean gross body weight change (g) & & -0.6 & -0.7 & -3.5 & -5.5 \\
\hline Mean gross body weight change (\%) & & -2 & -3 & -13 & -20 \\
\hline \multicolumn{6}{|l|}{ Liposomal doxorubicin8.0 mg/kg } \\
\hline Mean gross body weight (g) & 26.4 & 26.1 & 25.8 & 24.6 & 23.6 \\
\hline Mean gross body weight change (g) & & -0.3 & -0.6 & -1.8 & -2.8 \\
\hline Mean gross body weight change (\%) & & -1 & -2 & -7 & -11 \\
\hline \multicolumn{6}{|l|}{ DOX $8.0 \mathrm{mg} / \mathrm{kg}$} \\
\hline Mean gross body weight (g) & 26.1 & 25.4 & 24.5 & 21.5 & 19.3 \\
\hline Mean gross body weight change (g) & & -0.7 & -1.6 & -4.6 & -6.8 \\
\hline Mean gross body weight change (\%) & & -3 & -6 & -18 & -26 \\
\hline
\end{tabular}

change) compared to the control group.

\subsection{Daunorubicin}

The treatment with daunorubicin $10 \mathrm{mg} / \mathrm{kg}$, and daunorubicin orotate $12.43 \mathrm{mg} / \mathrm{kg}$ on Days 1,5 , and 9 was tolerated without deaths. Animals gained weight until Day 11. Thus, the MTD of daunorubicin HCI was above 10 $\mathrm{mg} / \mathrm{kg}$; for daunorubicin orotate, the MTD was $12.43 \mathrm{mg} / \mathrm{kg}$.

The daunorubicin doses were doubled on Day 11. Daunorubicin $20 \mathrm{mg} / \mathrm{kg}$ and daunorubicin orotate 24.86 $\mathrm{mg} / \mathrm{kg}$ were administered to mice on Days 11 and 15 . At these doses, mean body weight losses were observed on Day 17 for daunorubicin $\mathrm{HCl}$ (22\%) and daunorubicin orotate (9\%). As a result, the third injection, scheduled for Day 19, was cancelled. The treatments resulted in the deaths of all five animals in each group, occurring on Days 17, 19, and 21 for daunorubicin and Days 19, 20, and 21 for daunorubicin orotate.

Body weights on Day 17 in the group treated with daunorubicin $\mathrm{HCl}$ were significantly smaller $(\mathrm{P}<0.001)$ compared to body weights of mice in the group treated with daunorubicin orotate.

A summary of the tolerance experimental results, including mean gross body weight, mean gross body weight change, and percent change in mean body weight are presented in Table 5. Change in mean body weights over the course of the experiment in both groups is presented graphically in Figure 4.

\section{Discussion}

The goal of this study was to determine whether 1) DOX-O offers a potentially improved approach to cancer treatment, and 2) DOX-O retained the antitumor activity and reduced toxicity compared to DOX; and to inves- 


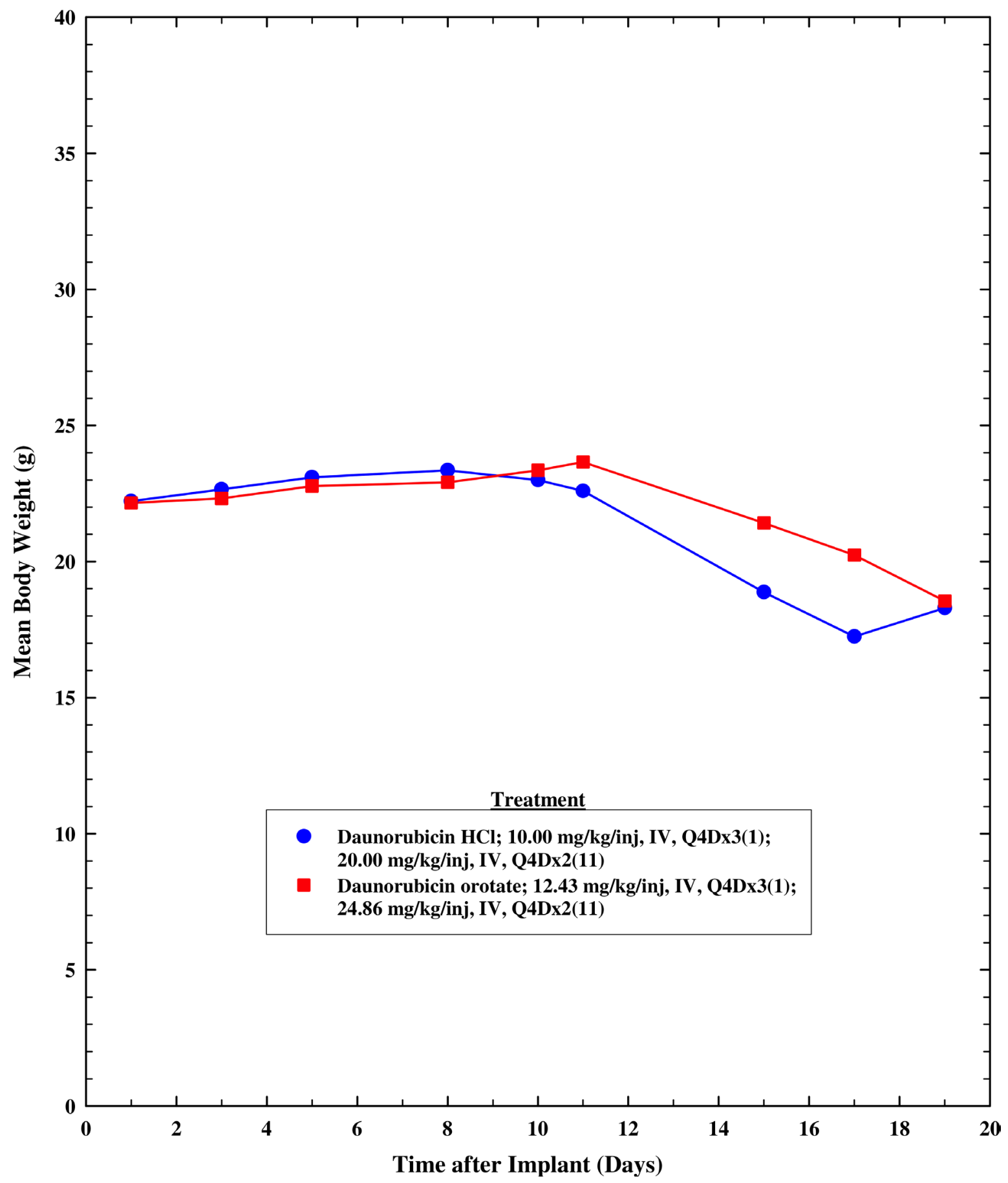

Figure 4. Effect of treatment with daunorubicin hcl and daunorubicin orotate on mean body weight of nontumor-bearing female athymic mice.

tigate the effects of various formulations of DOX on body weight. We compared the antitumor activity of DOX and DOX-O in CAKI-1 human renal tumor xenografts, investigated the accumulation of various formulations of DOX in heart and liver, and conducted tolerance studies with daunorubicin and its orotate salt.

We found that administration of DOX 8.0, 5.3, and $3.5 \mathrm{mg} / \mathrm{kg}$, and DOX-O at the equivalent dosages, 9.75, 6.5 , and $4.3 \mathrm{mg} / \mathrm{kg}$, was very effective in the inhibition of the growth of the CAKI-1 human renal tumor xenografts implanted s.c. in male NCr-nu/nu mice. Using tumor weight and tumor doubling time to measure an- 
Table 5. Mean gross body weight percent change daunorubicin tolerance.

\begin{tabular}{|c|c|c|c|c|c|c|c|c|}
\hline \multirow{2}{*}{ Compound } & \multicolumn{8}{|c|}{ Day } \\
\hline & 1 & 3 & 5 & 8 & 10 & 11 & 15 & 17 \\
\hline Daunorubicin & \multicolumn{5}{|c|}{10.00 mg/kg Q4Dx3 } & \multicolumn{3}{|c|}{$20.00 \mathrm{mg} / \mathrm{kg}$ Q4Dx2 } \\
\hline Mean gross body weight (g) & 22.2 & 22.7 & 23.1 & 23.4 & 23.0 & 22.6 & 18.9 & 17.3 \\
\hline Mean BW change (g) & & 0.5 & 0.9 & 1.2 & 0.8 & 0.4 & -3.3 & -4.9 \\
\hline Mean BW change (\%) & & 2 & 4 & 5 & 4 & 2 & -15 & -22 \\
\hline Daunorubicin orotate & \multicolumn{5}{|c|}{12.43 mg/kg Q4Dx3 } & \multicolumn{3}{|c|}{$24.86 \mathrm{mg} / \mathrm{kg}$ Q4Dx2 } \\
\hline Mean gross body weight (g) & 22.2 & 22.3 & 22.8 & 22.9 & 23.4 & 23.7 & 21.4 & 20.2 \\
\hline Mean BW change (g) & & 0.1 & 0.6 & 0.7 & 1.2 & 1.5 & -0.8 & -2.0 \\
\hline Mean BW change (\%) & & 0 & 3 & 3 & 5 & 7 & -4 & -9 \\
\hline
\end{tabular}

ti-tumor activity, we found that the difference in the tumor growth inhibition resulting from the administration of DOX and DOX-O was minimal, with DOX treatment resulting in greater inhibition of tumor growth. In addition to exhibiting similar anti-tumor activity, treatment with DOX-O was less toxic than DOX as indicated by lower body weight loss. These results suggest that DOX-O may be a safer formulation than DOX and offer a less toxic alternative for maintaining therapy.

The tumored animals given DOX $8.0 \mathrm{mg} / \mathrm{kg}$ and DOX orotate $9.75 \mathrm{mg} / \mathrm{kg}$ were sacrificed for drug concentration and heart histology studies. There was a $28 \%$ drop in DOX levels in the DOX-O group compared with DOX-HCl but this difference in DOX concentration in the heart was not statistically significant due to a high coefficient of variation. The mineralization and myofiber degeneration noted microscopically were observed only in treated animals; however, there was no definite test article-related pattern of occurrence, and these lesions may have been spontaneous events and not related to administration of DOX or DOX-O.

In the non-tumored animals, on Day 14 (the day after the last treatment), liposomal doxorubicin was associated with the lowest percentage of body weight loss, and DOX the highest percentage.

In the non-tumored animals, the liposomal doxorubicin concentration was found to be statistically significantly higher than that of DOX and DOX-O in heart tissue. The concentration of DOX in heart tissue in the group treated with DOX $8.0 \mathrm{mg} / \mathrm{kg}$ and DOX-O $9.75 \mathrm{mg} / \mathrm{kg}$ was similar, in contrast to the difference observed in the tumored animals.

Conversely, in concentration studies of the liver, while the concentration of DOX in the animals treated with liposomal doxorubicin was statistically higher than in the liver of animals treated with DOX-O or DOX, the concentration of DOX in the livers of animals treated with DOX-O was statistically higher than in the liver of the animals treated with DOX.

Orotate may confer protection against further ischemic stress upon recently infarcted hearts. In dogs, the function of infarcted hearts with ischemia was improved or restored with orotic acid therapy given 2 - 4 days post infarction. Orotic acid is thought to work by enhancing energy production by preventing ATP depletion and maintaining a cardiac supply of high-energy phosphate. Heart recovery is enhanced when OA stimulates uridine release from the liver, thereby potentially correcting myocardial pyrimidine deficiency and restoring depleted ATP stores [20].

Intravenous administration of daunorubicin $\mathrm{HCl} 10 \mathrm{mg} / \mathrm{kg}$ and daunorubicin orotate $12.43 \mathrm{mg} / \mathrm{kg}$ was well tolerated. Subsequent intravenous administration of daunorubicin $\mathrm{HCl} 20 \mathrm{mg} / \mathrm{kg}$ and daunorubicin orotate 24.86 $\mathrm{mg} / \mathrm{kg}$ was lethal. However, mice treated with daunorubicin orotate $24.86 \mathrm{mg} / \mathrm{kg}$ lost less weight prior to death than mice treated with daunorubicin $\mathrm{HCl} 20 \mathrm{mg} / \mathrm{kg}(\mathrm{P}<0.001)$. This difference in weight loss translates to a $13 \%$ improvement in tolerance to daunorubicin, measured by percent changes in animals' body weight when daunorubicin is given as orotate salt compared to daunorubicin given as chloride.

Change in body weight loss during primary chemotherapy is a strong prognostic factor for overall survival. Hess and colleagues [21] reported a significant relationship between median overall survival and weight change in ovarian cancer patients and recommended developing strategies to improve patient outcomes by minimizing 
weight loss during primary chemotherapy [21].

Rosenfeldt [20] reports that orotic acid, a component of cow's milk and pyrimidine biosynthesis intermediate, has been used in clinical practice for conditions including pernicious anemia, neonatal jaundice, hyperuricemia and artherosclerosis. Drug orotate derivatives release the drug as a charged molecule and free orotic acid, which in turn reduces drug-induced liver, heart, or other tissue toxicity. Free orotic acid has a negative charge and gets into cells by diffusion through the cell membranes. Orotic acid bound to a mineral or drug becomes a neutral salt and acquires lipophilic properties, making diffusion through lipid membranes easier. Drug orotate derivatives reduce drug-induced liver heart, or other tissue toxicity. The restructuring of toxic pharmaceutical agents to their orotate salts may preserve anti-tumor activity while offering a more favorable safety profile.

\section{Acknowledgements}

Studies were carried out under contract with Southern Research Institute, Birmingham, AL. We thank J. Abbott, who provided medical writing services on behalf of Tactical Therapeutics, Inc.

\section{References}

[1] Ali, M., Kamjoo, M., Thomas, H.D., Kyle, S., Pavlovska, I., Babur, M., Telfer, B.A., et al. (2011) The Clinically Active PARP Inhibitor AG014699 Ameliorates Cardiotoxicity but Does Not Enhance the Efficacy of Doxorubicin, Despite Improving Tumor Perfusion and Radiation Response in Mice. Molecular Cancer Therapeutics, 10, 2320-2329. http://dx.doi.org/10.1158/1535-7163.MCT-11-0356

[2] Burstein, H.J., Piccart-Gebhart, M.J., Perez, E.A., Hortobagyi, G.N., Wolmark, N., Albain, K.S., et al. (2012) Choosing the Best Trastuzumab-Based Adjuvant Chemotherapy Regimen: Should We Abandon Anthracyclines? Journal of Clinical Oncology, 30, 2179-2182. http://dx.doi.org/10.1200/JCO.2012.42.0695

[3] Healy-Bird, B.R. and Swain, S.M. (2008) Cardiac Toxicity in Breast Cancer Survivors: Review of Potential Cardiac Problems. Clinical Cancer Research, 14, 14-24. http://dx.doi.org/10.1158/1078-0432.CCR-07-1033

[4] Zoeller, L.S. (2012) Cardiotoxicity in Cancer Patients: Often More Malignant than Cancer. Interview. Oncology Statistics, 24.

[5] Lebrecht, D., Setzer, B., Ketelsen, U.P., Haberstroh, J. and Walker, U.A. (2003) Time-Dependent and Tissue-Specific Accumulation of mtDNA and Respiratory Chain Defects in Chronic Doxorubicin Cardiomyopathy. Circulation, 108, 2423-2429. http://dx.doi.org/10.1161/01.CIR.0000093196.59829.DF

[6] Volkova, M. and Russell, R. (2011) Anthracycline Cardiotoxicity: Prevalence, Pathogenesis and Treatment. Current Cardiology Reviews, 7, 214-2120. http://dx.doi.org/10.2174/157340311799960645

[7] Lenihan, D.J. and Cardinale, D.M. (2012) Late Cardiac Effects of Cancer Treatment. Journal of Clinical Oncology. 30(30), 3657-3664. Epub 2012 Sep 24.

http://dx.doi.org/10.1200/JCO.2012.45.2938

[8] Cardinale, D., Sandri, M.T., Martinoni, A., Borghini, E., Civelli, M., Lamantia, G., et al. (2002) Myocardial Injury Revealed by Plasma Troponin I in Breast Cancer Treated with High-Dose Chemotherapy. Annals of Oncology, 13, 710-715. http://dx.doi.org/10.1093/annonc/mdf170

[9] Giordano, S.H., Lin, Y.L., Kuo, Y.F., Hortobagyi, G.N. and Goodwin, J.S. (2012) Decline in the Use of Anthracyclines for Breast Cancer. Journal of Clinical Oncology, 30, 2232-2239. http://dx.doi.org/10.1200/JCO.2011.40.1273

[10] Wang, X., Liu, W., Sun, C.L., Armenian, S.H., Hakonarson, H., Hageman, L., et al. (2014) Hyaluronan Synthase 3 Variant and Anthracycline-Related Cardiomyopathy: A Report from the Children's Oncology Group. Journal of Clinical Oncology, 32, 647-653. http://dx.doi.org/10.1200/JCO.2013.50.3557

[11] Cardinale, D., Colombo, A., Torrisi, R., Sandri, M.T., Civelli, M., Salvatici, M., et al. (2010) Trastuzumab-Induced Cardiotoxicity: Clinical and Prognostic Implications of Troponin I Evaluation. Journal of Clinical Oncology, 28, 39103916. http://dx.doi.org/10.1200/JCO.2009.27.3615

[12] El-Sayyad, H.I., Ismail, M.F., Shalaby, F.M., Abou-El-Magd, R.F., Gaur, R.L., Fernando, A., et al. (2009) Histopathological Effects of Cisplatin, Doxorubicin and 5-Flurouracil (5-FU) on the Liver of Male Albino Rats. International Journal of Biological Sciences, 5, 466-473. http://dx.doi.org/10.7150/ijbs.5.466

[13] Childs, A.C., Phaneuf, S.L., Dirks, A.J., Phillips, T. and Leeuwenburgh, C. (2002) Doxorubicin Treatment in Vivo Causes Cytochrome C Release and Cardiomyocyte Apoptosis, as Well as Increased Mitochondrial Efficiency, Superoxide Dismutase Activity, and Bcl-2:Bax Ratio. Cancer Research, 62, 4592-4598.

[14] Safra, T. (2003) Cardiac Safety of Liposomal Anthracyclines. Oncologist, 8, 17-24. http://dx.doi.org/10.1634/theoncologist.8-suppl_2-17 
[15] Kohn, E.C., Reed, E., Sarosy, G.A., Minasian, L., Bauer, K.S., Bostick-Bruton, F., et al. (2001) A Phase I Trial of Carboxyamido-Triazole and Paclitaxel for Relapsed Solid Tumors: Potential Efficacy of the Combination and Demonstration of Pharmacokinetic Interaction. Clinical Cancer Research, 7, 1600-1609.

[16] Oliver, V.K., Patton, A.M., Desai, S., Lorang, D., Libutti, S.K. and Kohn, E.C. (2003) Regulation of the Pro-angiogenic Microenvironment by Carboxyamido-Triazole. Journal of Cellular Physiology, 197, 139-148. http://dx.doi.org/10.1002/jcp.10350

[17] Grover, G.J., Kelly, J., Moore, G., Jacoby, H., Karmali, R.A. and Gorman, G.S. (2007) Comparative Pharmacokinetic Profile of Carboxyamidotriazole and Carboxyamidotriazole-Orotate. Cancer Therapy, 5, 437-442.

[18] Corrado, C., Flugy, A.M., Taverna, S., Raimondo, S., Guggino, G., Karmali, R.A., et al. (2012) Carboxyamidotriazoleorotate Inhibits the Growth of Imatinib-Resistant Chronic Myeloid Leukaemia Cells and Modulates Exosomes-Stimulated Angiogenesis. PLoS One, 7, e42310. http://dx.doi.org/10.1371/journal.pone.0042310

[19] Karmali, R.A., Maxuitenko, Y. and Gorman, G. (2013) Treatment with Paclitaxel Orotate and Carboxyamidotriazole Orotate in SC-Implanted OVCAR-5 Human Ovarian Tumor Xenografts. Journal of Cancer Therapy, 4, 857-871. http://dx.doi.org/10.4236/jct.2013.44098

[20] Rosenfeldt, F.L. (1998) Metabolic Supplementation with Orotic Actic and Magnesium Orotate. Cardiovascular Drugs and Therapy, 12, 147-152.

[21] Hess, L.M., Barakat, R., Tian, C., Ozols, R.F. and Alberts, D.S. (2007) Weight Change during Chemotherapy as a Potential Prognostic Factor for Stage III Epithelial Ovarian Carcinoma: A Gynecologic Oncology Group Study. Gynecologic Oncology, 107, 260-265. 